\title{
Sexual Experience of Women after Gynecological Hysterectomy in the Department of Obstetrics and Gynecology of Yalgado Ouedraogo Teaching Hospital, Burkina Faso
}

\author{
Der Adolphe Somé ${ }^{*}$, Rélwendé Barnabé Yaméogo ${ }^{1}$, Souleymane Ouattara1, Dantola Paul Kain², \\ Béwendin Evélyne Komboigo², Blandine Thiéba Bonané ${ }^{2}$ \\ ${ }^{1}$ Department of Gynecology, Obstetrics and Reproductive Medicine, Souro Sanou University Teaching Hospital, Bobo-Dioulasso, \\ Burkina Faso \\ ${ }^{2}$ Department of Obstetrics and Gynecology, Yalgado Ouedraogo University Teaching Hospital, Ouagadougou, Burkina Faso \\ Email: *adolphesomeder@yahoo.fr
}

How to cite this paper: Somé, D.A., Yaméogo, R.B., Ouattara, S., Kain, D.P., Komboigo, B.E. and Bonané, B.T. (2019) Sexual Experience of Women after Gynecological Hysterectomy in the Department of Obstetrics and Gynecology of Yalgado Ouedraogo Teaching Hospital, Burkina Faso. Open Journal of Obstetrics and Gynecology, 9, 1273-1283.

https://doi.org/10.4236/ojog.2019.99123

Received: June 28, 2019

Accepted: September 14, 2019

Published: September 17, 2019

Copyright $\odot 2019$ by author(s) and Scientific Research Publishing Inc. This work is licensed under the Creative Commons Attribution International License (CC BY 4.0).

http://creativecommons.org/licenses/by/4.0/ (c) (i) Open Access

\begin{abstract}
Objective: To study the sexual experience of women after gynecological hysterectomy in the obstetrics and gynecology department of Yalgado Ouedraogo University Teaching Hospital in Burkina Faso. Patient and Method: We conducted a cross-sectional study from October 1, 2016 to March 30, 2017. It included any patient who had a gynecological indication for a hysterectomy in the Department of Obstetrics and Gynecology of Yalgado Ouedraogo University Teaching Hospital (CHU-YO) during the study period. A total of 85 patients were included. We collected information from the consultation records, clinical records, and operating room registries and by surveying the patients themselves. Result: The frequency of hysterectomy in the gynecological period was 3.9\%. The mean age of the patients was 51.71 (extremes: 35 and 66 years) and the mean parity was 4.8 . Married women were the majority. Fibromyoma and genital prolapse accounted for $56.47 \%$ and $23.53 \%$ respectively of operative indications. Regarding postintervention sexuality, $29.41 \%$ of women declared no longer having sexual desire. Also, they complained of vaginal dryness (31.8\%), decreased frequency of orgasm (42.3\%), dyspareunia (37.65). Sexual dysfunction was present in $82.35 \%$ of women. There was a statistically significant difference between global sexual functioning and geographic origin, educational attainment, socio-economic level, surgical approach, preintervention sexual counseling, women's psychological profile and their emotional relationship with their spouses. Conclusion: The psychosexual soundness of hysterectomy is important. A diagnosis of sexual disorders
\end{abstract}


prior to the intervention and psychological follow-up throughout the therapeutic process of the pathology indicative of a hysterectomy is necessary for successful postoperative sexuality.

\section{Keywords}

Sexual Experience, Gynecological Hysterectomy, Satisfaction, Ouagadougou, Burkina Faso

\section{Introduction}

Sexuality is the set of affects, fantasies, and behaviors related to the enjoyment of the body of another person and/or of his [1]. Hysterectomy is the surgical removal of the uterus that usually carries the body and cervix [2]. It is widely practiced in Western countries; 8.5\% of women in France or 72,000 interventions per year [3], 100,000 cases per year in England [4]; and 602,500 cases per year in the USA [6]; in Germany more than one-third of people have no uterus. In Africa, gynecological hysterectomy accounted for $2.8 \%$ of all surgical interventions in the CHU-YO Department of Obstetrics and Gynecology in 2013 and 5.9\% of activities in gynecological surgeries at Beijing Hospital in Dakar, Senegal, in 2014 [5].

The uterus being the symbol of femininity, sexuality and motherhood, its removal has consequences on the sexual and therefore affective life of the patients. A study carried out on the sexual experience of women after hysterectomy in October 2003 in the obstetrics and gynecology department of the Nantes Hospital in France showed that hysterectomy had no deleterious effects on erotic function [6]. Another study conducted at the Brazzaville Teaching Hospital from July 2014 to July 2015 on this subject also showed that all couples were satisfied sexually after treatment [1].

In Burkina Faso, the absence of a study on this subject and the increasing number of hysterectomies performed in the Department of Obstetrics and Gynecology of the Yalgado Ouedraogo Teaching Hospital (CHU-YO) motivated us to carry out this study.

\section{Materials and Method}

It was a cross-sectional study with a descriptive and analytical purpose. The data collection method was prospective from October 1, 2016 to March 30, 2017, for a period of six months.

We performed an exhaustive sampling of patients who had a hysterectomy with gynecological indication in the Department of Obstetrics and Gynecology at CHU-YO during the study period. Included in our sample was any patient who had an abdominal or vaginal gynecological hysterectomy in the Department of Obstetrics and Gynecology CHU/YO from October 1, 2016 to March 31, 2017. Each woman gave her verbal, free and enlightened agreement. We also got 
a written agreement of the general director of the hospital before undertaking this study. A total of 85 patients were finally included.

A sheet was used as the data collection carrier. Were collected social and democratic data: age, parity, number of deliveries, residence and marital status. Clinical records collected were essentially the indication of the operation, counseling, the postoperative complications and the duration of stay at the hospital after operation. Records of the operating room were the incision site, duration of the operation and any complication. We also did sexuality evaluation based on female sexual function index's score of Giuliano F 60 days after operation: through individual and direct interviews, women were invited to testify about their sexual experience since their gynecological hysterectomy. The collected data were entered using a microcomputer and analyzed with Epi info version 7.2.1.0. The statistical test used was Chi-square for the comparison of proportions. Statistical differences were considered significant for $\mathrm{p}$ less than 0.05 . The text processing was done using the Microsoft Office 2010 software.

\section{Results}

\subsection{Frequency}

During the study period, 85 gynecological hysterectomies were performed in the Gynecology Department, representing $3.98 \%$ of surgical procedures.

\subsection{Sociodemographic Characteristics}

The average age of the patients was 51.71 years with extremes of 35 and 66 years.

Of the patients operated on, $67.06 \%$ came from urban areas, $16.47 \%$ from the semi-urban environment and $16.47 \%$ from the rural areas. Women were illiterate in $43.53 \%$; those with secondary level of schooling accounted for $31.76 \%$; tertiary and primary level accounted respectively for $12.94 \%$ and $11.76 \%$ of patients. Housewives represented $42.30 \%$, employees $40 \%$ and traders $10.59 \%$. Married women were found in $70.59 \%$ of cases; widows were $9.41 \%$, concubines $5.88 \%$, single $1.18 \%$ and divorced women $12.94 \%$ of the sample.

The socioeconomic status was low, middle or high for respectively $32.94 \%$, $43.53 \%$ and $23.53 \%$ of the women of the study. The average number of gestations was 4.38 with extremes of 0 and 12 gestations. Those who got more than three gestations accounted for $41.18 \%$. The average parity was 4.8 with extremes of 0 and 12 deliveries. Of all our patients, $48.23 \%$ delivered at least for four times.

\subsection{Hysterectomy Data}

Distribution of patients according to the indication is presented in Table 1.

In this study, abdominal hysterectomy was performed in $62.35 \%$ of cases and the vaginal route in $37.65 \%$ of cases. Total hysterectomy was performed in $98.82 \%$ of cases and subtotal hysterectomy in $1.18 \%$ of cases.

Patients who did not receive preintervention sexual counseling accounted for $54.12 \%$; pre-intervention counseling was performed in $45.88 \%$ of patients. 
In $83.53 \%$ of the cases there was no intraoperative complication. Excluding minimal blood loss, an intraoperative complication was observed in $16.47 \%$ of cases, including $14.12 \%$ of intraoperative bleeding and $2.35 \%$ of bladder injury.

Operative follow-up was without complication in $67.06 \%$ of cases and complicated in $16.47 \%$ of cases. A fever was present in $5.87 \%$ of cases. Vesico-vaginal fistula and abdominal wall dehiscence were each found in $1.18 \%$ of cases.

Mean hospital stay was 4.7 days plus or minus 3.1 days with extremes of 2 and 24 days.

\subsection{Sexual Dysfunction after Hysterectomy}

The distribution of patients according to sexual dysfunction was reported in Table 2.

\subsection{Globalsexual Functioning According to Sociodemographic Data (Tables 3-7)}

There was a statistically insignificant association between globalsexual functioning and age. But patients between the ages of 35 and 45 were 3.1 times more satisfied than those who were 55 years of age or older.

There was a statistically significant link between global sexual satisfaction and origin. In addition, patients from urban areas had normal globalsexual functioning 4.2 times more than those from rural areas.

A statistically significant association between overall sexual functioning and

Table 1. Distribution of patients according to the indication of hysterectomy.

\begin{tabular}{ccc}
\hline Indication & $\mathrm{n}$ & $\%$ \\
\hline Fibromyoma & 48 & 56.47 \\
Genital prolapse & 20 & 23.53 \\
Cervical dysplasia & 7 & 8.23 \\
Suspicion of the cancer of the cervix & 4 & 4.71 \\
Suspicion of the cancer of the endometrium & 3 & 3.54 \\
Ovarian tumor & 1 & 1.18 \\
Others & 2 & 2.35 \\
Total & $\mathbf{8 5}$ & 100
\end{tabular}

Table 2. Distribution of patients according to sexual malfunction.

\begin{tabular}{ccc}
\hline Malfunction & Yes (\%) & No (\%) \\
\hline Desire & 29.4 & 70.6 \\
Excitement & 27 & 73 \\
Lubrication & 31.8 & 68.2 \\
Dyspareunia & 62.3 & 37.7 \\
Orgasm & 42.3 & 57.7 \\
Satisfaction & 46 & 54 \\
Global malfunction & 82.3 & 17.7
\end{tabular}


Table 3. Distribution of patients global sexual functioning relative to age.

\begin{tabular}{cccc}
\hline \multirow{2}{*}{ Age slice } & \multicolumn{2}{c}{ Global sexual functioning } & \multirow{2}{*}{ Total } \\
\cline { 2 - 3 } & Normal & malfunction & \\
\hline$<45$ & 5 & 15 & 20 \\
$45-54$ & 7 & 27 & 34 \\
$\geq 55$ & 3 & 28 & 31 \\
Total & $\mathbf{1 5}$ & $\mathbf{7 0}$ & $\mathbf{8 5}$ \\
\hline
\end{tabular}

$\mathrm{X}^{2}=1.51 \mathrm{P}=0.22 \mathrm{OR}_{1}=1.3$ and $\mathrm{OR}_{2}=3.1$.

Table 4. Distribution of patients global sexual functioning by geographic origin.

\begin{tabular}{cccc}
\hline \multirow{2}{*}{ Origin } & \multicolumn{2}{c}{ Global sexual functioning } & \multirow{2}{*}{ Total } \\
\cline { 2 - 3 } & Normal & malfunction & \\
\hline Urban & $13(23.21)$ & $43(76.79)$ & $56(100)$ \\
Semi-urban & $1(7.14)$ & $13(92.86)$ & $14(100)$ \\
Rural & $1(6.25)$ & $14(93.75)$ & $16(100)$ \\
Total & $15(17.65)$ & $70(82.35)$ & $85(100)$ \\
\hline
\end{tabular}

$\mathrm{X}^{2}=3.8 \mathrm{P}=0.041 \mathrm{OR}_{1}=3.9$ and $\mathrm{OR}_{2}=4.2$.

Table 5. Distribution of patients globalsexual functioning relative to educational attainment.

\begin{tabular}{cccc}
\hline \multirow{2}{*}{ Education attainment } & \multicolumn{2}{c}{ global sexual functioning } & \multirow{2}{*}{ Total } \\
\cline { 2 - 3 } & Normal & malfunction & \\
\hline Upper & $6(54.55)$ & $5(45.45)$ & $11(100)$ \\
Secondary & $6(22.22)$ & $21(77.78)$ & $27(100)$ \\
Primary & $2(18.18)$ & $9(81.82)$ & $11(100)$ \\
Uneducated & $1(2.78)$ & $35(97.22)$ & $36(100)$ \\
Total & $15(17.65)$ & $70(82.35)$ & $85(100)$ \\
\hline
\end{tabular}

$\mathrm{X}^{2}=19 \mathrm{P}=0.00001 \mathrm{OR}_{1}=4.2 ; \mathrm{OR}_{2}=5.4$ and $\mathrm{OR}_{3}=42$.

Table 6. Distribution of global sexual functioning versus Socio-economic level.

\begin{tabular}{cccc}
\hline \multirow{2}{*}{ Socio-economic level } & \multicolumn{2}{c}{ Global sexual function } & \multirow{2}{*}{ Total } \\
\cline { 2 - 3 } & Normal & malfunction & \\
\hline High & $6(27.3)$ & $16(72.7)$ & $22(100)$ \\
Medium & $8(23.5)$ & $26(76.5)$ & $34(100)$ \\
Low & $1(3.5)$ & $28(96.5)$ & $29(100)$ \\
Total & $\mathbf{1 5 ( 1 7 . 6 )}$ & $\mathbf{7 0 ( 8 2 . 4 )}$ & $\mathbf{8 5}(\mathbf{1 0 0 )}$ \\
\hline
\end{tabular}

$\mathrm{X}^{2}=3 \mathrm{P}=0.0004 \mathrm{OR}_{1}=1.2$ and $\mathrm{OR}_{2}=10.5$.

Table 7. Distribution of patients global sexual functioning relative to the occupation.

\begin{tabular}{cccc}
\hline \multirow{2}{*}{ Occupation } & \multicolumn{2}{c}{ Global sexual function } & \multirow{2}{*}{ Total } \\
\cline { 2 - 3 } & Normal & malfunction & \\
\hline Employed & $11(32.4)$ & $23(67.6)$ & $34(100)$ \\
Informal sector & $1(6.7)$ & $14(93.3)$ & $15(100)$ \\
housewives. & $3(8.3)$ & $33(91.7)$ & $36(100)$ \\
Total & $15(17.6)$ & $70(82.4)$ & $85(100)$ \\
\hline
\end{tabular}

$\mathrm{X}^{2}=9.8 \mathrm{P}=0.001 \mathrm{OR}_{1}=6.7$ and $\mathrm{OR}_{2}=5.3$. 
the education attainment of patients $(p=0.0001)$ has been found. In addition, patients with a higher level of education had normal global sexual functioning 42 times higher than patients who were not educated.

There was a statistically significant link between the global sexual functioning and the Socio-economic level of the patients $(\mathrm{p}=0.0004)$. In addition, patients with a high socio-economic level had normal global sexual functioning 10.5 times higher than those with a low socio-economic level.

A statistically significant link has been established between globalsexual satisfaction and the patient's occupation $(\mathrm{p}=0.001)$. In addition patients who were employed had normal global sexual functioning 5.3 times more than patients who were housewives.

\subsection{Globalsexual Functioning}

According to hysterectomy data a statistically insignificant association between overall sexual functioning and indications for hysterectomy was found ( $\mathrm{p}=$ $0.22)$; it was the same as the route of approach $(\mathrm{p}=0.12)$. In contrast, we noted a significant relationship between preintervention counseling and overall sexual functioning ( $\mathrm{p}=0.0014)$ Table 8 .

There was a statistically significant link between overall sexual functioning and pre-intervention sexuality counselling $(\mathrm{p}=0.0014)$. In addition, patients who received sexual counselling prior to the procedure had normal overall sexual functioning 8.3 times more than those who did not receive counselling

\section{Discussion}

\section{- Frequency}

The frequency of gynecological hysterectomy in our studywas 3.98\%; which is higher than the frequencies reported in Burkina Faso by Yonli [7] in 2010 and Bambara [8] in 2015, who found, respectively, 2.6\% and $2.8 \%$.

This difference may be attributable to the increase in the frequency of certain pathologies, such us fibromyoma, prolapse of uterus, and cervical tumors, the treatment of which sometimes require hysterectomy

\section{- Sociodemographic characteristics}

The average age of our patients was $51.71 \pm 7.4$ years with extremes of 35 years and 66 years. This result differs from those of Laassouli in Morocco [9],

Table 8. Distribution of patients overall sexual functioning compared to pre-intervention sexuality counseling.

\begin{tabular}{cccc}
\hline \multirow{2}{*}{ Global sexual function } & \multicolumn{2}{c}{ pre-intervention counseling } & \multirow{2}{*}{ Total } \\
\cline { 2 - 3 } & Yes & No & \\
\hline Normal & $11(73.33)$ & $4(26.67)$ & $15(100)$ \\
malfunction & $28(40)$ & $42(60)$ & $70(100)$ \\
Total & $39(45.88)$ & $46(54.12)$ & $85(100)$ \\
\hline
\end{tabular}

$\mathrm{X}^{2}=0.25 \mathrm{P}=0.0014 \mathrm{OR}_{1}=8.3$. 
which in 2012 had found an average age of 46.6 years; as well as for Buambo-Bamanga et al. in Congo-Brazzaville [10] in 2009, which reported an average age of 42.7 years. This difference could be explained by the increased number of patients in the age group of 50 to 54 years $(22.4 \%)$ in our study as well as the extreme ages of 35 and 66 years compared to that of Bambara [8] whose extremes were 20 and 76 years old.

The average parity was 3.8; corroborating the results of Bambara [8] who reported 4.3 deliveries per woman, and the average parity in Burkina Faso urban area, which is 4.6 children per woman, with a global fertility rate of 5.7 [11]. On the other hand, it is different from that of Diallo et al. which in Senegal in 2005 [12] recorded an average parity of 07 children in a series relating to vaginal hysterectomy whose indications were exclusively cases of genital prolapse, which are pathologies in which multiparity constitutes a risk factor.

The rate of married patients (70.6\%) was higher than the national rate of married women in the female population aged more than 12 years, which is $61.9 \%$ [13]. This rate could highlight a link between marital life and pathologies that require hysterectomy as part of the treatment.

The socioeconomic level was medium in $40 \%$ of patients. This rate is close to the country's 2006 poverty line, when $46.6 \%$ of the population were living below the poverty line estimated at $82672 \mathrm{XOF}$ per adult per year [11].

\section{- The indications of hysterectomy}

The most frequent indications were fibromyoma found in $56.47 \%$ of cases followed by genital prolapse (23.53\%) and cancerous and precancerous pathology of the cervix (12.94\%).

In relation to fibromyoma, Buambo-Bamanga et al. [10] in Congo Brazzaville in 2009, Yonli [7] in 2010 and Bambara in 2015 in Burkina Faso [8], Modupeola et al. [14] in Nigeria in 2009 reported frequencies of $63.9 \%, 63.8 \%, 51.1 \%$ and $61.8 \%$ respectively.

These high rates in all african studies are the expression of the racial factor of this pathology which constitutes a real public health problem in our tropics.

Regarding genital prolapse, in a study in Finland in 2009, Brummer et al. [15] reported $28 \%$ of genital prolapse among indications of gynecological hysterectomy; which is higher than that reported in our series (23.53\%).

For precancerous cervical pathology and gynecological cancers, our results are superior to those of Laassouli in Morocco [9] who found $03.1 \%$ of cases of cervical dysplasia and $34.2 \%$ of gynecological cancers. This difference could be explained by the fact that the fight against precancerous lesions including vaccination against HPV is better organized in Morocco where the health system is close to that of Europe (early detection and management). In addition, cervical cancer is an infectious disease and, therefore, is more frequent among the poor.

\section{- Effect of hysterectomy on sexuality}

In our studies, we noted that hysterectomy had no negative effect on desire, vaginal lubrication, excitement, orgasm and satisfaction with rates of $70.59 \%$; $68.23 \% ; 73 \% ; 57.65 \%$ and $54 \%$. These results corroborate those in the literature 
that reveal overall consequences that are most often beneficial to women and their sexuality if the indication of hysterectomy is licit [3] [16].

These positive effects may be explained by the consequences related to the problem that leads to hysterectomy because if the uterus is removed by surgery, is that there is a medical reason, now to cure or treat a problem generally has very positive impacts on the comfort of life, including on sexual comfort. On the contrary, a Quebec study on the sexual experiences of patients after gynecological hysterectomy showed that between $33 \%$ and $46 \%$ of women have trouble achieving arousal and orgasm after hysterectomy [17]. The diminution of orgasm for this author is explained by the functional consequences of hysterectomy because for the latter, at the moment of orgasm occur uterine contractions but without uterus, contractions disappear at this level. And the diminution of the excitement would be related to the anatomical consequences of the hysterectomy because to remove the uterus implies to cut tissues, thus to cut certain nerve fibers likely to innervate the sexual zone.

Dyspareunia was noted in $62.35 \%$ of cases. Our rate is lower than that of Graesslin O. et al. [17] who found 15\% of patients reporting painful intercourse. Postoperative dyspareunia are most often the indisputable responsibility of myorraphy and perineorraphy, which are often performed during vaginal hysterectomy.

For perimenopausal and menopausal sexually active women of our study (40\%), dyspareunia could be directly linked to the dryness of the vagina induced by menopause rather than being a complication of hysterectomy.

The women who experienced a global sexual malfunction after hysterectomy represented $82.3 \%$ of our sample.

Hysterectomy subject to compliance with basic rules of good practice (preparation for this act of excision, specific medical interview to demystify a gesture experienced by some women but also sometimes by their spouse as a break of their image of women, respect for fundamentals technics with primarily the preservation of sufficient vaginal length to allow a harmonious sexual act) does not obfuscate the result on sexual function [2].

The high rate of overall sexual malfunction recorded in our study could be explained by the lack of preparation of patients for hysterectomy.

The controversial impact of the age factor is also mentioned by some authors; for Ewert [18], young women under 40 would be most at risk for this parameter. These confirm the results of our study which reveal a high proportion of sexual malfunction because the average age of our patients was 51.71 years with extremes of 35 and 66 years.

\section{- Global sexual functioning according to sociodemographic data}

There was a statistically insignificant association between overall sexual functioning and age $(p=0.22)$. In contrast, a statistically significant association was found between geographic origin $(\mathrm{p}=0.041)$, educational attainment $(\mathrm{p}=$ $0.0004)$, and overall sexual functioning. 
Sexuality is becoming less taboo in urban areas than in rural areas because of access to the media and various sources dealing with sexuality. Indeed, to be schooled offers contribute to a better understanding of the sex life.

- Global sexual functioning according to the surgical approach and the counseling before hysterectomy

In our study, there was no statistically significant relationship between global sexual functioning after hysterectomy and the route of approach $(\mathrm{p}=0.12)$.

Two prospective studies comparing sexual function outcomes after vaginal and abdominal hysterectomy came to the same conclusion; this is the case of Costantini et al. [19] for the abdominal hysterectomy and that of Henni [20] et al. for the vaginal one which found no difference in the functional sexual results. Many studies and the review of the literature of Mokate in 2006 also go in this direction and do not find any difference for the feeling of sexuality according to operative techniques.

For some authors, sexual dysfunctions defined as being related to desire, arousal, orgasm and the existence of dyspareunia are dependent on certain psychological factors and not related to hysterectomy. These factors are: fear of the local consequences of a resumption of sexual activity; the fear of losing the partner, feelings of guilt and loss of interest.

According to the literature other factors unrelated to hysterectomy such as excision, spousal infidelity, the existence of spousal impotence, genital infections, infertility of the couple, menopause may be the origin of sexual dysfunction.

Unlike our study, Ayoubi et al. [21] noted that sexual deterioration appears to be more important for vaginal hysterectomies because of the absence of a visible scar and a more rapid recovery of activities. There was a statistically significant relationship between overall sexual functioning and pre-intervention counseling $(\mathrm{p}=0.0014)$. In addition, patients who received counseling before hysterectomy had a normal globalsexual functioning 8.3 times higher than those who underwent surgery without counseling.

That could be explained by the fact that, during the counseling, the woman and her partner are prepared to face the procedure, and they are given information about the condition and its management. That information contributes to making the condition and the procedure less dramatic for the patient and helps improve her sexual experience after the surgery.

\section{Limitations}

These difficulties stem primarily from the bias in relation to the cross-cutting nature of our study, which did not allow patients to be interviewed prior to the procedure.

The subjective, sensitive, modest and even taboo nature of the subjects about sexuality in our context could have influenced the responses of the patients interviewed.

The fact that some of the patients interviewed were circumcised could be a bias 
in our study because sexual disorders could also be related to female circumcision.

\section{Conclusion}

Hysterectomy subject to compliance with the basic rules of good practice does not obfuscate the result on sexual function. Sexual malfunctions defined as being related to desire, excitement, orgasm and dyspareunia would be dependent on psychological factors and not associated with hysterectomy. However, patients must be counseled by a psychologist before and after hysterectomy to minimize the psychic factors.

\section{Conflicts of Interest}

The authors declare no conflicts of interest regarding the publication of this paper.

\section{References}

[1] Mbongo, J.A., Mouanga, A., Miabaou, D.M., Nzelie, A. and Iloki, L.V. (2016) Qualité et vécu de la maladie avant et après hystérectomie vaginale, chez les femmes admises au Centre Hospitalier Universitaire de Brazzaville. Pan African Medical Journal, 25, 79. https://doi.org/10.11604/pamj.2016.25.79.10085

[2] Zucchi, A., Costantini, E., Mearini, L., Fioretti, F., Bini, V. and Porena, M. (2007) Female Sexual Dysfunction in Urogenital Prolapse Surgery: Colposacropexy vs. Hysterocolposacropexy. The Journal of Sexual Medicine, 5, 139-145. https://doi.org/10.1111/j.1743-6109.2007.00570.x

[3] Pad, D. and Arnold, E.P. (1994) Sexual Function after Pelvic Surgery in Women. Australian and New Zealand Journal of Obstetrics and Gynaecology, 34, 471-474. https://doi.org/10.1111/j.1479-828X.1994.tb01274.x

[4] Clayton, R.D. (2006) Hysterectomy. Obstetrics \& Gynecology, 20, 73-87. https://doi.org/10.1016/j.bpobgyn.2005.09.007

[5] Levêque, J. (2006) Sexualité normale et ses troubles. CHU Hôpital Sud Rennes. Université de Rennes 1, 8 p.

[6] Careme, L.R., Berthier, A., Sentilhes, L., Collard, P. and Grise, P. (2008) Analyse de la sexualité féminine dans une population féminine française. Progrès en Urologie, 18, 527-535. https://doi.org/10.1016/j.purol.2008.03.035

[7] Yonli, D.S. (2010) Aspects épidémiologiques et pronostic des hystérectomies. Thèse. Med. Université de Ouagadougou (UFR/SDS), No. 2, 91 p.

[8] Bambara, T.S. (2015) Les hystérectomies gynécologiques dans le département de gynécologie et d'obstétrique du CHU/YO (Ouagadougou). Thèse Med. Université de Ouagadougou (UFS/SDS), No. 47, 54-56.

[9] Laassouli, M. (2012) Les indications de l'hystérectomie. A propos de 2158 cas. Th Méd Université Mohammed V de Raba t(Maroc), No. 23, 97.

[10] Buambo-Bamanga, S.F., Oyere, M.P., Doukaga, M.R.A. and Ekoundzola, J.R. (2009) Hystérectomie d'indication gynécologique au centre hospitalier et universitaire de Brazzaville. Clinic Mother Child Health, 6, 1113-1116.

[11] Institut National des Statistiques et de la Démographie (INSD) (2008) Recensement général de la population et de l'habitation de 2006. Résultats définitifs Burkina Faso. Juillet, 952-964. 
[12] Diallo, D., Sys, M.R., Gueye, K.M.S. and Moreau, J.C. (2005) L'hystérectomie par voie vaginale à la clinique gynécologique du CHU Aristide Le Dante. Méd. d Afro Noire, 52, 376-378.

[13] Von Théobald, P. and Chevret, M. (1999) Chirurgie génito-urinaire et troubles de la sexualité. Constat, 10, 1-2.

[14] Modupeola, S., Adesiyun, A.G., Agunbiade, O.A. and Duro, M.A. (2009) ClinicoPathological Assessment of Hysterectomies in Zaria. European Journal of General Medicine, 6, 150-153. https://doi.org/10.29333/ejgm/82660

[15] Brummer, T.H., Jalknen, J. and Freser, J. (2009) National Prospective 1 Year Survey of 5279 Hysterectomies. Human Reproduction, 24, 2515-2522.

[16] D’argent, D. (1996) La sexualité après hystérectomie ou beaucoup de bruit pour pas grand-chose. Contraceptif Fertile Sexa, 24, 347-349.

[17] Graeslin, O., Martin-Morille, C., Laguiller-Amour, M.C., D’Arnaud, T., Gonzales, N., Bancher, F., Lever, M., Bor, J.P., Harika, G., Gabriel, R. and Qu'Evreux, C. (2002) Enquête régionale sur le retentissement psychique et sexuel à court terme de l'hystérectomie. Gynécologie Obstétrique \& Fertilité, 30, 474-482. https://doi.org/10.1016/S1297-9589(02)00370-3

[18] Eweert, B., Slang en, T. and Van Haendel, B. (1995) Sexualité acter laparoscopicassisted vaginal hystérectomie. The Journal of the American Association of Gynecologic Laparoscopists, 3, 27-32.

[19] Costantini, E., Mearini, L., Bini, V., Zucchi, A., Mearini, E. and Porena, M. (2005) Utérus Préservation in Surgical Correction of Urogenital Prolepse. European Urology, 48, 642-649. https://doi.org/10.1016/j.eururo.2005.04.022

[20] Henni, M., El-Tough, T. and Katsimanis, E. (2003) Sacrospinous Cervico Colpopexy with Utérine Conservation for Utero Vaginal Prolepse in Elder Woman: An Revolving Concept. American Journal of Obstetrics \& Gynecology, 188, 645-650. https://doi.org/10.1067/mob.2003.75

[21] Ayoubi, J.M., Fanchin, R., Monrozies, X., et al. (2003) Respective Consequences of Abdominal, Vaginal, and Laparoscopie Hysterectomies on Women Sexuality. The European Journal of Obstetrics \& Gynecology and Reproductive Biology, 111, 179182. https://doi.org/10.1016/S0301-2115(03)00213-6 